\title{
LABORATORY EXPERIMENTS AND DEVICES TO STUDY PLASMA SURFACE INTERACTION
}

\author{
G.J. van Rooij \\ FOM-Institute for Plasma Physics Rijnhuizen, Association EURATOM-FOM \\ Edisonbaan 14, 3439 MN Nieuwegein, The Netherlands; www.rijnh.nl
}

\begin{abstract}
Laboratory experiments are widely used to study plasma surface interaction issues for fusion research. In this paper it is described why dedicated experiments for PSI are advantageous and what the requirements are to reach the parameter regime relevant for ITER. An overview is given of some typical devices, particularly PISCES-B, PSI-2 (nowadays JULE-PSI), Nagdis, Pilot-PSI, and Magnum-PSI, along with selected results to illustrate their capabilities.
\end{abstract}

\section{INTRODUCTION}

The interaction between plasma and the material wall of a fusion device has become a discipline in its own right within fusion research (eg. [1]). In earlier days it was merely a matter of optimization of confinement of the core plasma by minimizing the inflow of impurities that are generated at the walls. This has led to the application of low $\mathrm{z}$ wall materials and the development of the divertor configuration. Nowadays, the challenges lie down in the development of a material wall in combination with plasma scenarios that ensure prolonged operation of ITER [2] and fusion reactors beyond ITER such as DEMO. The issues are retention of the fuel (a safety issue for ITER and a problem for the fuel cycle for future fusion energy plants), life time of the wall, and formation of dust (again merely a safety issue).

The proximity of a plasma to a surface results in a wide variety of processes that well may interfere. These include chemical erosion and physical sputtering, association and recombination, formation of clusters of molecules, redeposition, hydrogen retention. Together, these form the complex 'plasma surface interaction' (PSI). It is obvious that it is difficult to diagnose, understand, and predict the outcome of these processes. This becomes even worse if the plasma conditions that are encountered are as diverse as all the PSI processes that are involved, as is inevitably the case in a fusion experiment.
It is difficult to study the PSI physics in present day fusion devices, especially if it concerns the conditions that are expected for ITER. Especially the exposure times relevant for ITER are not met and certainly not in combination with the expected extreme particle and power loads. Also a critical aspect is the inaccessibility of the wall and in particular the divertor in fusion devices. Firstly, this means that it is not easy to change (parts of) the wall material to quickly test different candidate targets. It also means that targets studied post mortem have faced a wide range of different experimental conditions so that it will be very hard to correlate them with the observed damage. Similarly, diagnostic access for in situ studies limited.

Several linear plasma generators are operational in the world. Table 1 lists the main operational parameters of a few that are especially active on plasma-surface interactions: PISCES (Plasma Interaction with Surface and Components Experimental Simulator) at the University of California, San-Diego [3], NAGDIS (Nagoya University Divertor Simulator) [4], PSI in Berlin [5, 6], which has been moved to Juelich and is nowadays called JULE-PSI[7] and LENTA [8] at Kurchatov Institute in Moscow. Studies at these devices have led to a progress in understanding of processes relevant for a tokamak divertor. Some phenomena were even first discovered at linear plasma generators and later observed in tokamaks. For example, a detached regime in helium and hydrogen plasma as well as appearance of plasma flow reversal were discovered and investigated at PISCES-A [9]. A series of PSI studies at moderate flux densities was carried out at these linear apparatuses. To give an impression of the wide range of investigated subjects, we mention several of them. Measurements of erosion mechanisms from solid (carbon, tungsten) and liquid materials (gallium and lithium) were performed at the PISCES-B apparatus [10]. Experiments with hydrogen plasma at NAGDIS-II were devoted to the role of molecular activated recombination in the plasma detachment $[11,12]$. A series of experiments on the interaction of helium plasma with tungsten surfaces was conducted at the NAGDIS-I set-up [4, 13]. Studies at PSI-1 fo- 
Table 1: Parameters of various experiments for PSI in the world. PIG = Penning Ionisation gauge; CA $=$ Cascaded Arc; Magnum-PSI data are specifications.

\begin{tabular}{l|c|c|c|c|c|c}
\hline \hline & NAGDIS-II & PSI-2 & PISCES-B & LENTA & Pilot-PSI & Magnum-PSI \\
\hline Type source & PIG & PIG & PIG & e-Beam & CA & CA \\
Power [kW] & 10.5 & 50 & 85 & 7.5 & 45 & 270 \\
Pressure source $[\mathrm{Pa}]$ & 10 & $0.1-1$ & $0.1-1$ & & $10^{4}$ & $10^{4}$ \\
Pressure target [Pa] & 0.1 & $0.01-0.1$ & $10^{-3}-1$ & $0.2-7$ & $1-10$ & $<10$ \\
$T_{i}$ target $[\mathrm{eV}]$ & 50 & $<15$ & $10-500$ & 5 & $0.1-5$ & $0.1-10$ \\
$T_{e}$ target $[\mathrm{eV}]$ & 10 & $<30$ & $3-50$ & $0.5-20$ & $0.1-5$ & $0.1-10$ \\
$n_{i}$ target $\left[m^{-3}\right]$ & $6 \cdot 10^{19}$ & $10^{19}$ & $10^{17}-10^{19}$ & $10^{19}$ & $10^{21}$ & $10^{20}$ \\
Ion flux target $\left[\mathrm{m}^{-2} s^{-1}\right]$ & $10^{22}$ & $10^{22}$ & $10^{21}-10^{23}$ & $5 \cdot 10^{21}$ & $2 \cdot 10^{25}$ & $10^{24}$ \\
$B[T]$ & 0.25 & 0.1 & 0.04 & 0.2 & 1.6 & 3 \\
Beam diameter target $[\mathrm{cm}]$ & 2 & $6-15$ & $3-20$ & 2.5 & 1.5 & 10 \\
Distance to target $[\mathrm{m}]$ & 2.8 & 2.5 & 1.5 & 2 & $0.5-1$ & $1.0-1.5$ \\
\hline
\end{tabular}

cused on chemical sputtering of carbon based materials at high ion flux densities of deuterium plasma [14, 15]. Investigations on high-frequency and microwave radiation from the zone of interaction of hydrogen and helium plasma streams with neutral background gas targets were performed at LENTA linear plasma generator [16]. Also the development of a liquid lithium surface as a candidate for a reactor first wall [17] and imitation of deuterium plasma interaction with tungsten surfaces [18] and carbon materials [19] were carried out at this device.

All of the above mentioned plasma generators can produce hydrogen, deuterium and helium plasma with electron densities $10^{18}-5 \cdot 10^{20} \mathrm{~m}^{-3}$, flux densities in the range of $10^{21}-10^{23} \mathrm{~m}^{-2} \cdot \mathrm{s}^{-1}$, and operate in a magnetic field of $0.1-0.3 \mathrm{~T}$. Unfortunately, this does not cover the conditions that are expected for ITER (these will be estimated in the next paragraph) at least by an order of magnitude in the flux density. To bridge this gap, FOM-Rijnhuizen is constructing a new linear plasma generator, Magnum-PSI [21]. It aims at providing a 10 $\mathrm{cm}$ diameter plasma beam with hydrogen plasma flux density $10^{24} \mathrm{~m}^{-2} \mathrm{~s}^{-1}$ at a temperature of $1-5 \mathrm{eV}$, in a magnetic field of $3 \mathrm{~T}$. Design issues for Magnum-PSI, in particular the development of a plasma source that produces the required plasma fluxes, are investigated in a smaller device that is presently operational, PilotPSI. In the mean time, Pilot-PSI has demonstrated to be capable of producing these fluxes, albeit in a smaller beam diameter and in pulsed magnetic fields of $1.6 \mathrm{~T}$. This makes the device already a unique tool for PSI studies in the extreme flux regime.

In this paper the emphasis will be on Pilot-PSI results to illustrate the capability of linear machines for PSI research. In addition, some important results of other machines are mentioned and cited to give a complete picture. But first the requirements with respect to particle and power fluxes that are expected for the ITER divertor will be estimated to set the framework for the recent developments at the FOM Institute Rijnhuizen.

\section{PARTICLE AND POWER FLUXES EXPECTED IN THE ITER DIVERTOR}

The starting point for these rough estimations is the ITER objectives and capabilities: $500 \mathrm{MW}$ of fusion power, produced with $\sim 50 \mathrm{MW}$ of heating power. Power that is exhausted from the core plasma of ITER will be directed to the target of the divertor. A large part will be radiated away, but still $25 \%$ will reach the divertor. The power losses $P_{\text {loss }}$ are estimated as one fifth of the fusion power (i.e. the fusion energy ending up in helium) plus the ignition power:

$$
P_{\text {loss }}=150 M W \text {. }
$$

So, a quarter of this power is transported in the scape off layer (SOL) to the target over a connection length $L_{\|} \sim 100 \mathrm{~m}$. The width of the SOL follows from the ratio between the parallel and cross field heat conduction, which is classically equal to:

$$
\frac{\kappa_{\|}}{\kappa_{\perp}} \propto\left(\omega_{c e} \tau_{e i}\right)^{2} \approx 10^{4}
$$

This yields for the width of the SOL:

$$
L_{\perp}=L_{\|}\left(\frac{\kappa_{\|}}{\kappa_{\perp}}\right)^{-1} \propto 100 m \times 10^{-4} \approx 10^{-2} \mathrm{~m} .
$$

The power fall-off length in present day devices, which is also expected for ITER, is indeed close to this value: 5 $\mathrm{cm}$. With the main radius of ITER being $R=6.2 \mathrm{~m}$, the 
parallel power density reaching the target is estimated as:

$$
q_{\|} \approx \frac{P_{\text {loss }}}{4 \pi R L_{\perp}} \approx 50 \frac{M W}{m^{2}} .
$$

This power is directed onto the target under an angle (the angle of the field line to the target in the poloidal plane). A typical value for this so-called flux expansion is 10 .

$$
q_{\text {target }}=q_{\|} / 10 \approx 5 \frac{M W}{m^{2}} .
$$

To put this number in perspective: it is a tenth of the power at the surface of the sun. The particle flux density follows form the sheath voltage, which is typically assumed to be five times the electron temperature $T_{e}$. For ITER it is imperative that $T_{e}$ is below $\sim 10 \mathrm{eV}$ because otherwise the acceleration of light impurities over the sheath voltage leads to physical sputtering of the wall material. This yields for the particle flux:

$$
\Gamma_{\text {ion }}=\frac{q_{\text {target }}}{e V_{\text {sheath }}}=\frac{q_{\text {target }}}{5 e T_{e}} \approx 10^{24} m^{-2} s^{-1} .
$$

\section{PRODUCTION OF LOW TEMPERATURE PLASMA}

A common concept to produce the low temperature plasma in a linear experiment is acceleration of electrons that are emitted from a heated $\mathrm{LaB}_{6}$ cathode to a ring anode. This geometry is very similar to that of a Penning Ionization gauge. It is for example in use at the PISCES and PSI experiments. In order to produce electron currents up to $40 \mathrm{~A} / \mathrm{cm}^{2}$, the cathode is indirectly heated to $\sim 1800^{\circ} \mathrm{C}$ with tungsten filaments. Total cathode currents of 500-1000 A are common. The pressure inside the source is low, typically at most several Pa. A more detailed description of this source type is given by Goebel et al. [22]. An important advantage of this type of source is that its pressure is compatible with high vacuum conditions.

In order to make a large step in flux densities (and total fluxes), the Pilot-PSI relies on a high pressure source: the cascaded arc [23, 24]. Figure 1 shows a schematic overview of the source, which consists of tungsten cathodes in an ionization chamber, a stack of water-cooled copper plates and a nozzle. A central bore in the plates forms the discharge channel, presently 4-7 $\mathrm{mm}$ diameter and $3 \mathrm{~cm}$ length. Gas is introduced into the cathode chamber at a pressure of typically $10^{4} \mathrm{~Pa}$. It is heated by the electron current emitted from the cathode tips, thus creating a plasma. In turn, these cathode tips are heated by the impact of ions that are accelerated upstream over the negative potential of the cathodes. The large pressure difference with the vacuum vessel downstream makes the plasma to expand

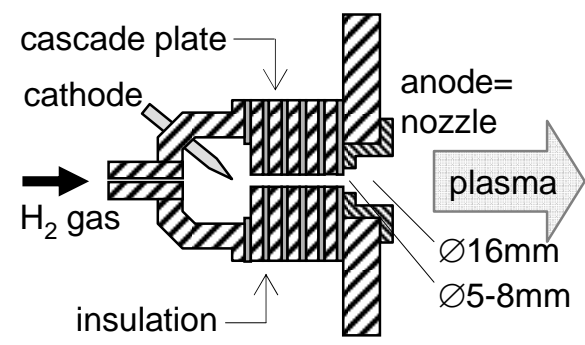

Figure 1: Schematic of the cascaded arc as it is used to produce hydrogen plasma in Pilot-PSI. A central bore of $4 \mathrm{~mm}$ diameter in 5 electrically insulated watercooled plates forms the $30 \mathrm{~mm}$ length plasma channel. Hydrogen flows at several $\operatorname{sim}\left(2.5 \mathrm{slm}=1.0 \times 10^{21}\right.$ $\mathrm{H}_{2} / \mathrm{s}$ ) into the cathode chamber at $10^{4} \mathrm{~Pa}$, the discharge current is stabilized to $\sim 10^{2} \mathrm{~A}$.

into the vessel. Due to the large pressure inside the ionization channel, the electrons and ions are well coupled in temperature via Coulomb collisions [25]. These temperatures are typically $1-3 \mathrm{eV}$ as the plasma is at the lower end of the Saha equilibrium [24]. Fig. 2 shows as a function of the magnetic field the plasma conditions that are routinely produced in Pilot-PSI with this cascaded arc. It is seen that the magnetic field plays a crucial role for the plasma density. If it would be absent, the densities would be orders of magnitude lower. In that case, the plasma would freely expand and drop in temperature. At temperatures below $\sim 1 \mathrm{eV}$, recombination via molecular processes becomes efficient and at the relatively high pressures at which the Pilot-PSI is operated ( $\sim 1 P a$, due to the large gas inflow from the source)

\section{ON THERMAL EQUILIBRIUM AND POWER TRANSPORT}

The characteristics of the plasma produced by these two different types of plasma sources differ significantly. Firstly, the equilibrium between the electron and ion temperature is dependent on the source pressure. This is illustrated by Fig. 3 The high pressure cascaded arc operates at typically $10^{3}-10^{4} \mathrm{~Pa}$, which is in the region where the electron temperature $T_{e}$ and the heavy particle temperature $T_{h}$ are close to equilibrium and are of order $1 \mathrm{eV}$. The low pressure sources operate at a pressure that is typically 2 orders of magnitude lower. The graph shows that this uncouples the two temperatures and increases the electron temperature towards $10 \mathrm{eV}$.

The pressure difference has also an impact on the plasma convection speed. In the low pressure sources, this speed is typically of the order of $100 \mathrm{~m} / \mathrm{s}$, whereas in the cascaded arc the plasma is accelerated to sound 


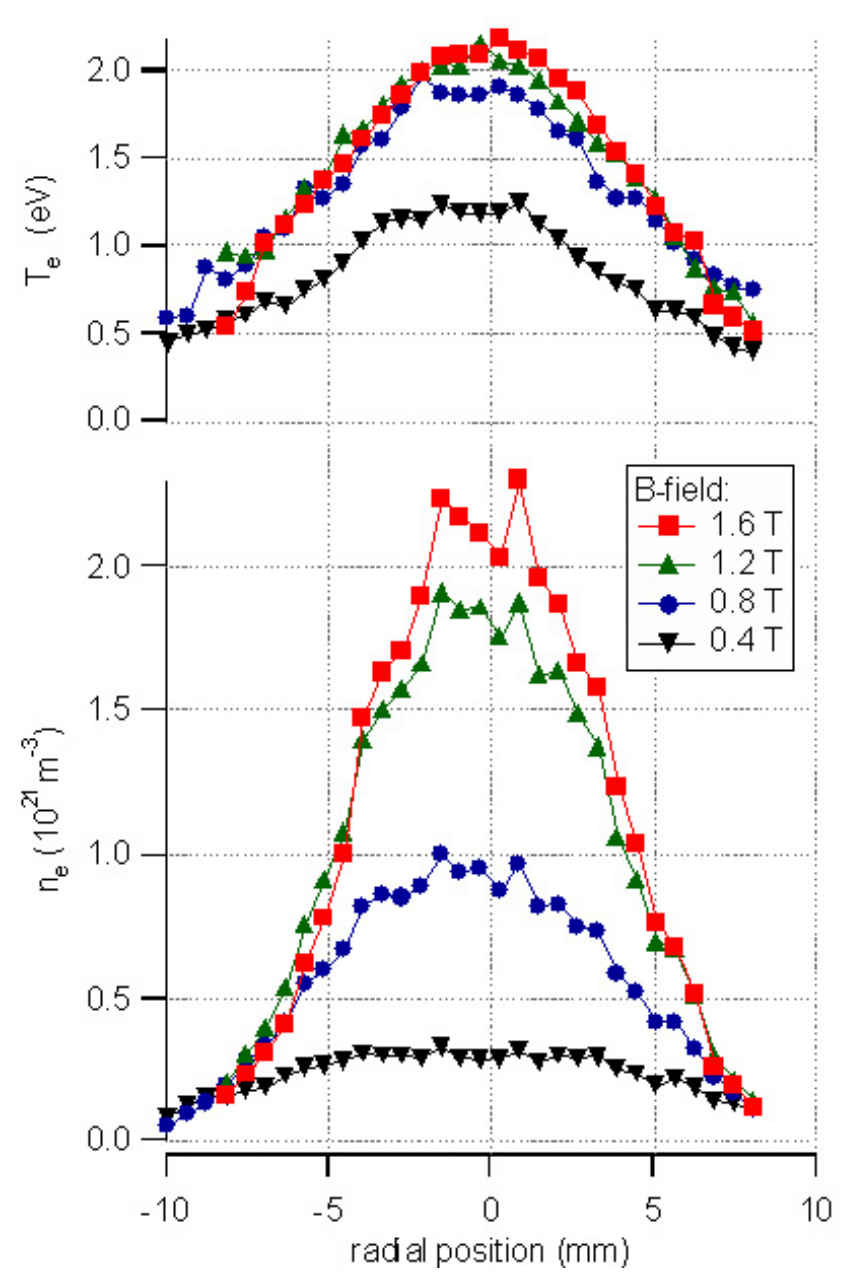

Figure 2: Hydrogen plasma conditions measured with Thomson scattering [26] in Pilot-PSI.

speed, i.e. $10^{4} \mathrm{~m} / \mathrm{s}$. The consequence is that in the former case power conduction is dominant, whereas in the latter case plasma convection is the main transport mechanism. Let's calculate the power convection and conduction for the two source types to illustrate this difference. The heat conductivity parallel to the magnetic field is $\kappa_{\|}=10^{3} T_{e}^{5 / 2}$, i.e. $\sim 2 \times 10^{3} \mathrm{~W} / \mathrm{m} / \mathrm{eV}$ at $1 \mathrm{eV}$ and $\sim 6 \times 10^{5} \mathrm{~W} / \mathrm{m} / \mathrm{eV}$ at $10 \mathrm{eV}$. Assuming a temperature difference of $1 \mathrm{eV}$ over a length of $1 \mathrm{~m}$, this gives the same numbers in $\mathrm{W} / \mathrm{m}^{2}$. The parallel thermal heat convection is $5 / 2 k\left(T_{e}+T_{i}\right) n_{e} v_{\text {plasma }}$, which is $\sim 5 \times 10^{5} \mathrm{~W} / \mathrm{m}^{2}$ and $\sim 5 \times 10^{4} \mathrm{~W} / \mathrm{m}^{2}$ for the high and low pressure source example, respectively.

\section{SELECTION OF RESULTS OBTAINED AT LIN- EAR PLASMA GENERATORS}

In the introduction already a wide range of applications were indicated with references to relevant liter-

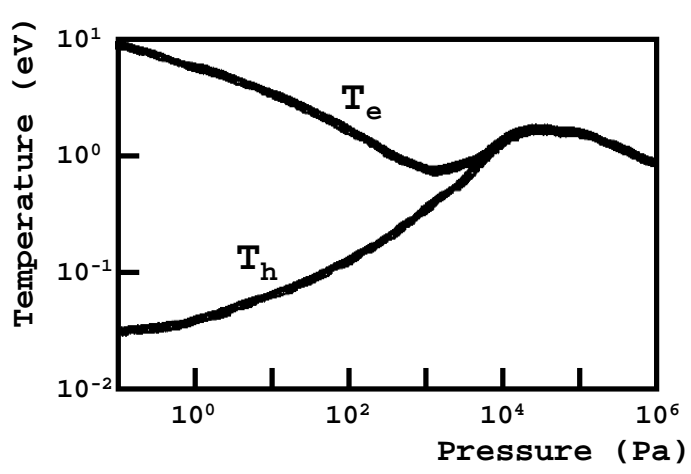

Figure 3: Schematic of the behavior of the electron temperature $T_{e}$ and heavy particle temperature $T_{h}$ in a discharge as a function of the pressure.

ature. Here only a small selection is discussed and an emphasis is put on recent results of Pilot-PSI.

An issue that has and is being intensively being studied with linear plasma generators is the erosion of carbon, remaining one of the concerns for the design of ITER. Recently, first experiments have been performed on carbon erosion in Pilot-PSI. This was the first time that the extreme flux density regime was entered. Until then, the record flux density in a linear plasma generator for erosion experiments had been $10^{23} \mathrm{D}^{+} / \mathrm{m}^{2} \mathrm{~s}$, realized in PSI-2 [14]. The measurements discussed here served predominantly to manifest the high fluxes and operation conditions that we can cover. The fine grain carbon targets (R 6650, SGL Carbon Group; $\oslash 26 \times 2.4$ $\mathrm{mm}$ ) were clamped on a water cooled copper heat sink at $0.56 \mathrm{~m}$ from the nozzle of the plasma source. A series of over 10 exposures was carried out to a single target with the following experimental parameters: $7 \mathrm{~mm}$ bore discharge channel, $\mathrm{B}=0.4 \mathrm{~T}, 100 \mathrm{~s}$ exposure time, discharge current $100 \mathrm{~A}$ to $200 \mathrm{~A}$, gas flow $0.2 \mathrm{slm}$ to 0.5 $\operatorname{slm}$ (setting the neutral pressure in the vessel to 0.35 and 1.6 Pa, respectively). The target was grounded and a net electron current of up to $\mathrm{I}_{\text {target }}=59 \mathrm{~A}$ (depending on the discharge current and the gas flow) was measured to the target (where higher neutral pressures led to a lower net current to the target). The erosion was characterized by analyzing the target surface ex situ with a profilometer. The result is shown in Fig. 4 It is very likely that during the different exposures different mechanisms (e.g., chemical erosion, sublimation, radiation enhanced sublimation, localized heating due to anode spot formation) were important. So the material loss cannot be interpreted in terms of a chemical erosion yield. However, what can be concluded is that significant redeposition occurred. In volume more than half of the eroded material is found back at the sides of the crater. It is very striking that this redeposition zone is within the plasma wetted area. It is 


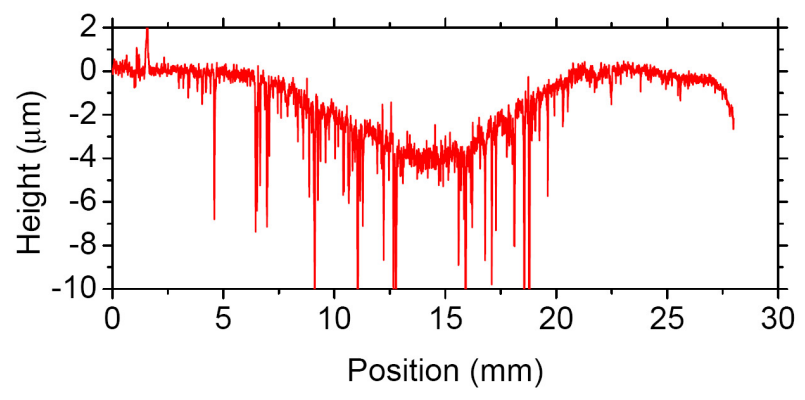

Figure 4: Erosion crater of a fine grain carbon target exposed to ITER relevant plasma fluxes in Pilot-PSI measured ex situ with a profilometer.

presently the challenge to understand this in terms of plasma conditions and to benchmark these experimental results with numerical transport codes.

Molecular spectroscopy was performed on the $\mathrm{CH}$ band to quantify the chemical erosion [27]. In this approach, the intensity of the $\mathrm{CH}$ band is compared with the $H_{\gamma}$ line to determine the erosion yield. The plasma flux density was determined from Thomson scattering measurements at $18 \mathrm{~mm}$ in front of the target by calculating the sheath flux from the measured density and temperature. In this way, the famous Roth curve (the flux dependence of the carbon chemical erosion yield) [28] was extended with a data point at a flux density of $2 \cdot 10^{24} \mathrm{~m}^{-2} \mathrm{~s}^{-1}$.

The PISCES-B machine is unique in the sense that it is capable of studying the effect of Be impurities in the plasma on the interaction with the target. This is generally referred to as "mixed materials" studies. A good example is the erosion of carbon and the hydrogen retention by tungsten being influenced by Be impurities. A recent paper by Doerner et al. [29] gives a good overview of the present understanding. For mixed $\mathrm{Be} / \mathrm{C}$ surfaces this is summarized as:

- Be ions are accelerated over the sheath potential and gain enough energy to be implanted. This will lead to the formation of beryllium carbide $\left(B e_{2} C\right)$.

- The formation of the beryllium carbide in the carbon surface will reduce chemical erosion and physical sputtering.

- The layer of beryllium carbide will reach a maximum thickness and subsequently arriving Be will not bond as a carbide and will be more easily eroded.

- Beryllium is the main species that is eroded from a carbon surface with a $\mathrm{Be}_{2} \mathrm{C}$ layer.

\section{DESIGN OF MAGNUM-PSI}

The Magnum-PSI device is presently operated with conventional coils similarly to Pilot-PSI[30]. The device will be upgraded to a super conducting magnet system. A schematic of the device is shown in Figure 5[31]. The cascaded arc source used in Pilot-PSI is being scaled up to produce the plasma in Magnum-PSI. Scaling studies predict power efficiencies in excess of $10 \%$. Like in Pilot- PSI, the plasma will be additionally heated by Ohmic dissipation (of current to the target or to a ring electrode in front of the target) and RF heating. Pressure control is essential for efficient plasma transport to the target as well as ITER relevant neutral densities at the target. Three stage differential pumping based on roots pumps compatible with the large influx of neutral hydrogen will maintain pressures of $\sim 1 \mathrm{~Pa}$ in the exposure chamber as is confirmed by modelling and experiments on Pilot-PSI. The superconducting magnet has been predesigned and will have a bore of $1.3 \mathrm{~m}$ and a length of $2.5 \mathrm{~m}$, with $2 \times 8$ room temperature diagnostic ports. It will be placed on rails so that it can be moved for access to the vacuum vessel. This vessel consists of three elements (the source-, heating-, and target chamber) that can be modified if necessary. The target chamber has been designed for optimal diagnostic access. Magnum-PSI will allow targets with a width of $<10 \mathrm{~cm}$ and a length of $<60 \mathrm{~cm}$. The sample manipulator allows tilting to grazing incidence, rotation and axial translation, and will have $100 \mathrm{~kW}$ cooling capacity. Targets are exchanged in the target analysis chamber, where also first surface analysis can be performed.

\section{ACKNOWLEDGMENTS}

This work, supported by the European Communities under the contract of Association between EURATOM/FOM, was carried out within the framework of the European Fusion Programme with financial support from NWO.

\section{REFERENCES}

1. G. FEDERICI, C.H. SKINNER, J.N. BROOKS, J.P. COAD, C. GRISOLIA, A.A. HAASZ, A. HASSANEIN, V. PHILIPPS, C.S. PITCHER, J. ROTH, W.R. WAMPLER, D.G. WHYTE, Nucl. Fusion 41, 1967 (2001).

2. ITER PHYSICS BASIS EDITORS, Nucl. Fusion 47, (2007).

3. D. GOEBEL, G. CAMPBELL, AND R.W. CONN, J. Nucl. Mater. 121, 27 (1984).

4. M.Y. YE, S. TAKAMURA, N, OHNO, J. Nucl. Mater. 241-243, 1243 (1997). 


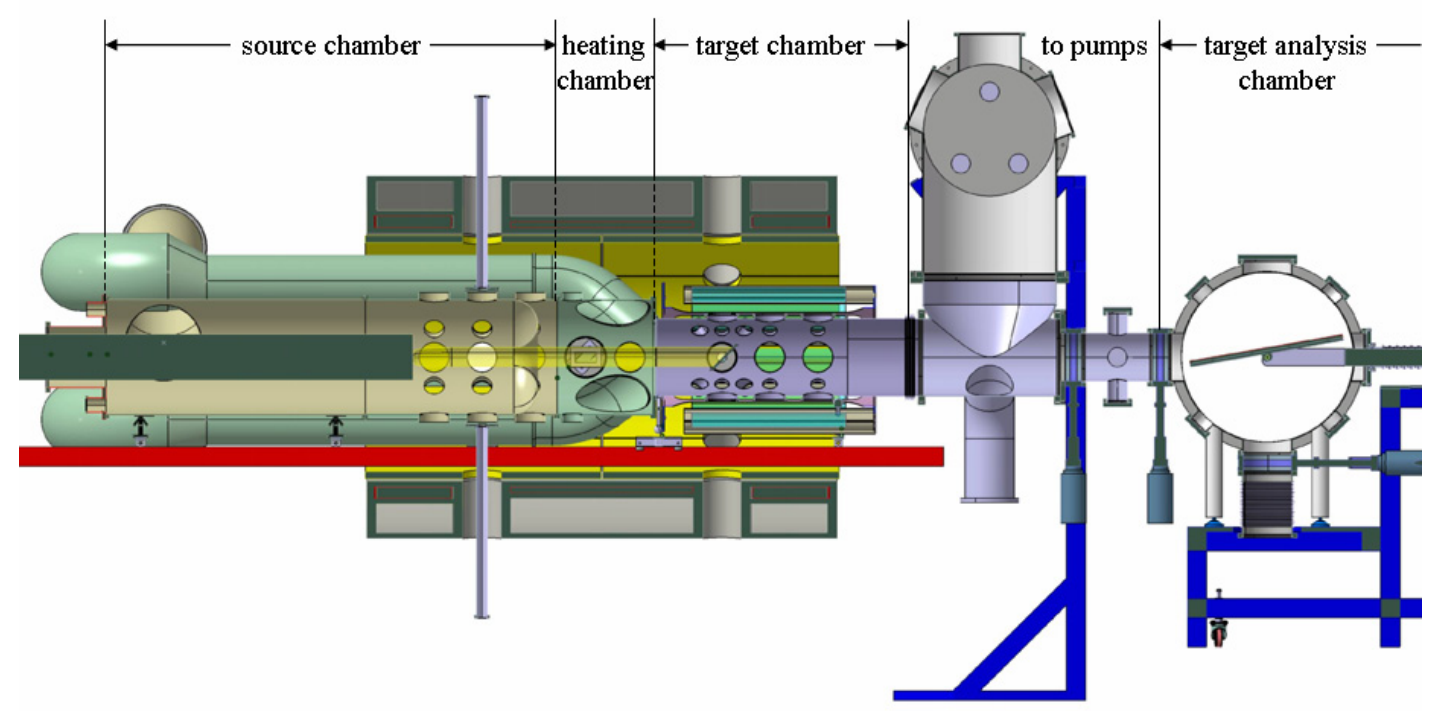

Figure 5: Total overview of the Magnum-PSI experiment with target station and target manipulator. Shown are (from left to right) the source-, heating- and target chamber with pump ducts. Next to these, the pumping station for the third stage is shown. On the right hand side, the target station with target and target manipulator are visible. In the target analysis station, the targets can be analyzed in detail with surface analysis equipment.

5. H. MEYER, S. KLOSE, E. PASCH, G. FUSSMANN, Phys. Rev. E 61, 4347 (2000).

6. T. LUNT, G. FUSSMANN, O. WALDMANN, Phys. Rev. Lett. 100, 175004 (2008).

7. B. UNTERBERG et al., Fusion Eng. Des. 86, 1797 (2011).

8. A.M. LITNOVSKY. Ph.D. thesis. Moscow Engineering Physics Institute (2001) (in Russian).

9. L. SCHMITZ, B.MERRIMAN, L. BLUSH, R. LEHMER, R.W. CONN, R. DOERNER, A. GROSSMAN, F. NAJMABADI, Phys. Plasmas 2(8), 3081 (1995)

10. R.P. DOERNER, M.J. BALDWIN, R.W. CONN, A.A. GROSSMAN, S.C. LUCKHARDT, R. SERAYDARIAN, G.R. TYNAN, D.G. WHYTE, J. Nucl. Mater. 290-293, 166-172 (2001)

11. N. OHNO, N. EZUMI, S. TAKAMURA, S.I. KRASHENINNIKOV, A. YU. PIGAROV, Phys. Rev. Lett., 81818 (1998)

12. N. EZUMI, D. NISHIJIMA, H KOJIMA, J. Nucl. Mater. 266-269, 337, (1999)
13. M.Y. YE, K.KUDOSE, T. KUWABARA, N. OHNO, S. TAKAMURA, J. Nucl. Mater. 266269, 742 (1999)

14. P KORNEJEW, W. BOHMEYER, H.-D. REINER, C.H. WU, Phys. Scr. T91 29, (2001).

15. H. GROTE, W. BOHMEYER, P. KORNEJEW, H.-D. REINER, G. FUSSMANN, R. SCHLOGL, G. WEINBERG, C. H. WU, Chemical Sputtering Yields of Carbon Based Materials at High Ion Flux Densities. J. Nucl. Mater. 266-269, 1059-1064 (1999)

16. A.M. LITNOVSKY, B.I. KHRIPUNOV, G.V. SHOLIN, V.B. PETROV, V.V. SHAPKIN, N.V. ANTONOV, J. Nucl. Mater. 290-293, 1107 (2001)

17. B.I. KHRIPUNOV, V.B. PETROV, V.V. SHAPKIN, A.S. PLESHAKOV, A.S. RUPYSHEV, N.V. ANTONOV, A.M. LITNOVSKY, D.YU. PROKHOROV, YU. S. SHPANSKY, V.A. EVTIKHIN, I.E. LYUBLINSKY, A.V. VERTKOV, J. Nucl. Mater. 313-316, 619-624 (2003) 
18. M.I. GUSEVA, V.I. VASILIEV, V.M. GUREEV, L.S. DANELYAN, B.I. KHRIPUNOV, S.N. KORSHUNOV, V.S. KULIKAUSKAS, YU.V. MARTYNENKO, V.B. PETROV, V.N. STRUNNIKOV, V.G. STOLYAROVA V.V. ZATEKIN, A.M. LITNOVSKY, J. Nucl. Mater. 290-293, $1069(2001)$

19. S.N. KORSHUNOV, M.I. GUSEVA, V.M. GUREEV, L.S. DANELYAN, B.I. KHRIPUNOV, B.N. KOLBASOV, V.S. KULIKAUSKAS, A.M. LITNOVSKY, YU.V. MARTYNENKO, V.B. PETROV, V.V. ZATEKIN, J. Nucl. Mater. 313-316, 87-91 (2003)

20. S. KLOSE, W. BOHMEYER, M. LAUX, H. MEYER, G, FUSSMANN, AND THE PSI-TEAM, Contrib. Plasma Phys., 41, 467-472 (2001)

21. J. WESTERHOUT, W.R. KOPPERS, W.A.J. VIJVERS, R.S. AL, S. BREZINSEK, S. BRONS, H.J.N. VAN ECK, R. ENGELN, B. DE GROOT, R. KOCH, H.J. VAN DER MEIDEN, M.P. NUIJTEN, V. PHILIPPS, M.J. VAN DE POL, P.R. PRINS, U. SAMM, J. SCHOLTEN, D.C. SCHRAM, B. SCHWEER, P.H.M. SMEETS, D.G. WHYTE, E. ZOETHOUT, A.W. KLEYN, W.J. GOEDHEER, N.J. LOPES CARDOZO, G.J. VAN ROOIJ, Phys. Scr. T128 35 (2007).

22. D.M. GOEBEL Y. HIROOKA, T.A. SKETCHLEY, Rev. Sci. Instrum. 561717 (1985)

23. G.J. VAN ROOIJ, V.P. VEREMIYENKO, W.J. GOEDHEER, B. DE GROOT, A.W. KLEYN, P.H.M. SMEETS, T.W. VERSLOOT, D.G. WHYTE, R. ENGELN, D.C. SCHRAM, AND N.J. LOPES CARDOZO, Appl. Phys. Lett. 90, 121501 (2007).

24. W.A.J. VIJVERS, D.C. SCHRAM, A.E. SHUMACK, N.J. LOPES CARDOZO, J. RAPP, G.J. VAN ROOIJ, Plasma Sources Sci. Technol. 19, 065016 (2010).

25. A.E. SHUMACK, V.P. VEREMIYENKO, D.C. SCHRAM, H.J. DE BLANK, W.J. GOEDHEER, H.J. VAN DER MEIDEN, W.A.J. VIJVERS, J. WESTERHOUT, N.J. LOPES CARDOZO, G.J. VAN ROOIJ, Phys. Rev. E 78, 046405 (2008).

26. G.J. vAN ROOIJ, H.J. VAN DER MEIDEN, M.H.J. 'T HOEN, W.R. KOPPERS, A.E. SHUMACK, W.A.J. VIJVERS, J. WESTERHOUT, G.M. WRIGHT, J. RAPP, Plasma Phys. Controlled Fusion 51124037 (2009).
27. J. WESTERHOUT, N.J. LOPES CARDOZO, J. RAPP, G.J. VAN ROOIJ, Appl. Phys. Lett. 95151501 (2009).

28. J. ROTH et al, J. Nucl. Mater. 337-339 971 (2004).

29. R.P. DOERNER, M. BALDWIN, J. HANNA, CH. LINSMEIER, D. NISHIJIMA, R. PUGNO, J. ROTH, K. SCHMID, A. WILTNER, Phys. Scr. T128 115 (2007).

30. H.J.N. VAN ECK, A.W. KLEYN, A. LOF, H.J. VAN DER MEIDEN, G.J. VAN ROOIJ, J. SCHOLTEN, P.A.Z. VAN EMMICHOVEN, Appl. Phys. Lett. 101, 224107 (2012).

31. H.J.N. VAN ECK, W.R. KOPPERS, G.J. VAN ROOIJ, W.J. GOEDHEER, B. DE GROOT, P. SMEETS, J. SCHOLTEN, M. VAN DE POL, S. BRONS, R. KOCH, B. SCHWEER, U. SAMM, V. PHILIPPS, R.A.H. ENGELN, D.C. SCHRAM, N.J. LOPES CARDOZO, A.W. KLEYN, Fusion Eng. Des. 821878 (2007). 